Marquette University

e-Publications@Marquette

College of Nursing Faculty Research and

Publications

Nursing, College of

$1-2021$

\title{
Intensive Care Unit Nurse: Could We Call a Palliative Care \\ Consult? Intensive Care Unit Provider: It's Too Early. Palliative Care Integration in the Intensive Care Unit: The Struggle to Translate Evidence Into Practice
}

\author{
Natalie S. McAndrew \\ University of Wisconsin - Milwaukee \\ Jill L. Guttormson \\ Marquette University, jill.guttormson@marquette.edu \\ Sean Marks \\ Medical College of Wisconsin \\ Mary Rhodes \\ Medical College of Wisconsin \\ Jayshil Patel \\ Medical College of Wisconsin
}

See next page for additional authors

Follow this and additional works at: https://epublications.marquette.edu/nursing_fac

Part of the Nursing Commons

\section{Recommended Citation}

McAndrew, Natalie S.; Guttormson, Jill L.; Marks, Sean; Rhodes, Mary; Patel, Jayshil; and McCracken, Colleen, "Intensive Care Unit Nurse: Could We Call a Palliative Care Consult? Intensive Care Unit Provider: It's Too Early. Palliative Care Integration in the Intensive Care Unit: The Struggle to Translate Evidence Into Practice" (2021). College of Nursing Faculty Research and Publications. 889.

https://epublications.marquette.edu/nursing_fac/889 
Authors

Natalie S. McAndrew, Jill L. Guttormson, Sean Marks, Mary Rhodes, Jayshil Patel, and Colleen McCracken

This article is available at e-Publications@Marquette: https://epublications.marquette.edu/nursing_fac/889 
Marquette University

e-Publications@Marquette

Nursing Faculty Research and Publications/College of Nursing

This paper is NOT THE PUBLISHED VERSION.

Access the published version via the link in the citation below.

Dimensions of Critical Care Nursing, Vol. 40, No. 1 (January/February 2021): 51-58. DOl. This article is (C) Lippincott Williams \& Wilkins, Inc. and permission has been granted for this version to appear in $\underline{\mathrm{e}}-$ Publications@Marquette. Lippincott Williams \& Wilkins, Inc. does not grant permission for this article to be further copied/distributed or hosted elsewhere without the express permission from Lippincott Williams \& Wilkins, Inc.

\section{Intensive Care Unit Nurse: Could We Call a Palliative Care Consult? Intensive Care Unit Provider: It's Too Early. Palliative Care Integration in the Intensive Care Unit: The Struggle to Translate Evidence Into Practice}

Natalie S. McAndrew

College of Nursing, University of Wisconsin-Milwaukee, Milwaukee, WI

Jill Guttormson

College of Nursing, Marquette University, Milwaukee, WI

Sean Marks

Division of Hematology \& Oncology, Palliative Care Section, Medical College of Wisconsin, Milwaukee, WI 


\section{Mary Rhodes}

Division of Hematology \& Oncology, Palliative Care Section, Medical College of Wisconsin, Milwaukee, WI

\section{Jayshil Patel}

Division of Pulmonary and Critical Care Medicine at Medical College of Wisconsin, Milwaukee, WI

\section{Colleen McCracken}

Inpatient Oncology Unit at Froedtert \& the Medical College of Wisconsin Froedtert Hospital, Milwaukee, WI

\section{Abstract}

Despite evidence regarding the value of palliative care, there remains a translation-to-practice gap in the intensive care setting. The purpose of this article is to describe challenges and propose solutions to palliative care integration through the presentation and discussion of a critical care patient scenario. We also present recommendations for a collaborative palliative care practice framework that holds the potential to improve quality of life for patients and families. Collaborative palliative care is characterized by close working relationships with families, interprofessional intensive care unit healthcare teams, and palliative care specialists. The shortage of palliative care specialists has become a pressing policy and practice issue and highlights the importance of increasing primary palliative care delivery by the intensive care team. Underexplored aspects of collaborative palliative care delivery include the interprofessional communication required, identification of key skills, and expected outcomes. Increased recognition of intensive care unit palliative care as a process of engagement among nurses, providers, patients, and their family members heralds a vital culture shift toward collaborative palliative care. The interprofessional palliative specialist team has the expertise to support intensive care teams in developing their primary palliative skills and recognizing when specialist palliative care support is required. Promotion of strategic palliative care delivery through this collaborative framework has the potential to decrease suffering among patients and families and reduce moral distress among healthcare professionals.

There have been numerous calls for policy changes to improve the quality of end-of-life care in the United States. ${ }^{1-4}$ In the intensive care unit (ICU), interprofessional teams of palliative care specialists (who provide subspecialty palliative care) are consulted in ICUs to work with patients with serious illness and their families to facilitate collaborative patient- and family-centered decision making, improve symptom management, and provide support to patients and families. ${ }^{5,6}$ However, palliative care specialists may be underused in the ICU, ${ }^{7-}$ ${ }^{10}$ in part because of a shortage of palliative care specialists. ${ }^{11}$ Given that early and ongoing palliative care throughout a patient's illness trajectory has been shown to be beneficial to patients and families, many ICU patients, not just the most complex critically ill, may benefit from this holistic approach to care. ${ }^{12}$

To meet the immense need for palliative care in ICUs, interprofessional ICU teams must develop primary palliative care skills, also called basic palliative care or generalist palliative care, and integrate these skills into their practice to support patients and families in less complicated cases or when palliative care specialists are not consulted. 5,6,12 We will use the term primary palliative care in this article, defined as palliative care delivered by healthcare professionals who are not palliative care specialists working within the subspeciality of palliative care. ${ }^{6}$ Primary palliative care includes discussions about goals and values with patients and their families, assessing and intervening to address distressing symptoms, and incorporating support resources such as spiritual support professionals, social workers, or child life specialists, who can address a variety of patient and family psychosocial needs. ${ }^{13}$ Importantly, integrated palliative care is a model in which ICU 
healthcare professionals practice primary palliative care and consult palliative care specialists who provide subspeciality palliative care to address the complex needs of patients and families in the ICU setting. ${ }^{13}$ In a recent survey of 181 physicians, nurses, administrators, and other ICU healthcare professionals, $78 \%$ reported that integrating palliative care was important; however, these professionals also reported barriers to integrated palliative care in the ICU, including a lack of confidence in their own palliative care skills. ${ }^{8}$ Furthermore, although primary palliative care is an expectation and best practice, ${ }^{14}$ there is limited understanding of how ICU teams conceptualize and deliver primary palliative care to patients and families in the ICU setting. A lack of metrics for organizations to determine the quality and quantity of primary palliative care delivery in the ICU is further indication of a gap in translation to practice. ${ }^{15}$

The purpose of this article is to describe challenges and propose solutions to palliative care integration through the presentation and discussion of a critical care patient scenario. We also present a collaborative palliative care practice framework that holds the potential to improve quality of life for patients and families. Collaborative palliative care is characterized by close working relationships with patients and their families, interprofessional ICU teams, and palliative care specialists.

\section{SETTING THE STAGE: A PATIENT CASE}

The following scenario illustrates missed opportunities to support a critically ill patient and his family using both primary and specialty palliative care. This case is based on a compilation of the authors' clinical experiences in the ICU setting.

Henry is a 63-year-old man with end-stage liver disease who is ineligible for a liver transplant. He has been resistant to advance care planning discussions initiated by his primary care providers and specialists. Henry was recently hospitalized for altered mental status and experiences a respiratory arrest on a medical floor. He undergoes endotracheal intubation and is admitted to the ICU, where he remains on mechanical ventilation, continuous dialysis, and vasopressors. The nurses recognize signs that Henry is deteriorating and begin to worry about whether he will survive his ICU stay.

Henry's wife, Betty, now makes all medical decisions on his behalf. His status remains guarded and Henry's wife is struggling to cope with the situation. The nurses are challenged with supporting Betty while managing the patient's labile blood pressures that require minute-to-minute assessment and intervention. Betty is tearful, interacts minimally with the staff, and spends most of her time in the corner of Henry's ICU room or in the waiting room. Her adult children visit infrequently. The nurses are having difficulty making a connection with Betty and are uncertain of the best support resources to help her cope.

One nurse is finally able to converse with Betty during the night shift. The nurse identifies that Betty is suffering physically, emotionally, spiritually, and socially. Betty expresses that she is feeling extreme fatigue, and has no friends or family who can help with day-to-day activities at home. She also reveals that her 4 children have a difficult relationship with Henry because of his alcoholism, which is why they rarely visit. Betty talks about the comfort she gets from going to her church, but mentions that she stopped attending services when Henry's illness worsened as she was worried about leaving him alone due to his intermittent confusion. Betty has been questioning her relationship with God and cannot make sense of why this situation is happening to her. She feels alone and isolated and misses better days with Henry. She tells the nurse that they had been planning their 50th wedding anniversary with a trip to Paris; however, now she does not even know if he will live. After this revelation, she begins sobbing uncontrollably. In the midst of this conversation, the nurse's attention is diverted to a long list of immediate caregiving activities for Henry. She notes he is grimacing with every nursing care she performs. As she is also concerned about Henry's pain management, the nurse makes a note to herself to tell 
the day shift nurse to ask the ICU team to initiate a palliative care consult for pain management and family support.

The next day, when the day shift nurse asks for a palliative consult, she is told by the attending that it is too soon to get palliative care specialists involved. The ICU attending explains that he has been rounding daily with Betty and that Betty is able to perform her role as Henry's decision maker. Because the attending perceives that Betty is confident about the goals of care, he does not think a palliative consult is appropriate at this time. The day nurse is swept up with other pressing tasks and misses the opportunity to communicate in detail to the attending the concerns of the night shift nurse that arose from her conversation with Betty. The night shift nurse returns the next evening for her shift and is upset that a palliative specialist was not consulted. She experiences moral distress because she feels, as Betty and Henry's advocate, she was unheard and asks the charge nurse to assign Henry to a different nurse.

The ICU team's service has a heavy volume of families requiring decision-making support. Intensive care unit providers continue to round with Betty and have been honest with her that Henry is unlikely to survive. Henry makes a few small improvements in the next few days, and then his status begins to wane again. The ICU team revisits goals of care discussions but Betty does not want to stop any treatment; she feels that Henry would want everything done no matter what. The ICU team asks Betty to reconsider a Do Not Resuscitate order, but she insists Henry remain a full code. The ICU provider team continues to focus on aggressive care, hoping that in time, Betty will accept the inevitable outcome. Henry remains unresponsive on life support for the next 3 months without palliative care specialist involvement. As time goes by in the ICU, there are fewer meetings with Betty and the ICU team. Betty becomes more and more withdrawn and spends most of her time outside the ICU in the waiting room. One day, Betty asked the nurse caring for Henry if he was suffering. The nurse responded that she was not sure, but that he was grimacing frequently despite his continuous pain medication infusion. Betty nods and begins to cry.

Henry eventually experiences cardiopulmonary arrest and dies despite resuscitation efforts. Henry's original night nurse observes this futile attempt to resuscitate him, experiences profound moral distress again, and considers leaving her job at the hospital. After her husband's death, Betty experiences anxiety, depression, and complicated grief due to her concerns about Henry's suffering and the daunting financial obligations for his prolonged stay in the ICU.

\section{CASE ANALYSIS}

Scenarios similar to this are all too common in the ICU setting. Prolonged, aggressive treatment that ends in a long-anticipated death can be traumatic for patients, families, and healthcare professionals. In this scenario, the ICU team offered Betty limited primary palliative care by identifying Betty as a decision maker and involving her in a discussion of the patient's values and goals when making a decision about code status. However, other aspects of primary palliative care went unaddressed, such as adequate pain management for Henry, and Betty's spiritual, emotional, physical, and social quality of life concerns. In the presented scenario, it was apparent early on that medical reality was unlikely to align with family hopes. In addition, family distress over decision making and lack of adequate team support led to a fracturing of team morale. Involving palliative care specialists earlier in Henry's ICU stay and/or in ICU team discussions about strategies to promote primary palliative care for Henry and his wife may have facilitated more collaborative decision making and, ultimately, a more holistic approach to patient and family support.

Our scenario illustrates a theme in the ICU nursing literature: nursing concerns about patient suffering that lead to nurse moral distress ${ }^{16-19}$ and burnout. ${ }^{20}$ Interprofessional collaboration among palliative care specialists and ICU teams has the potential to reduce prolonged patient suffering, decrease nurse and physician moral distress, 
increase consideration of support resources for patients and families, and lead to more patient and family engagement. ${ }^{21-23}$ There was a clear need for subspeciality palliative care in this scenario; however, throughout the case, the wife would also have benefited from a more collaborative, interprofessional approach to primary palliative care. A collaborative approach to palliative care would have addressed many of the challenges presented in our scenario and is a vital area for research, practice improvement, and policy development to promote routine, high-quality palliative care in the ICU.

\section{CONNECTION TO THE LITERATURE}

The social, professional, and financial ramifications of missed palliative care opportunities for patients, families, healthcare professionals, and organizations are far-reaching. An important aspect of palliative care is helping families navigate challenging medical decisions. End-of-life decisions become increasingly complicated as lifeprolonging technology continues to advance. Notably, a quarter of US healthcare spending is allocated to the small percentage (6\%) of individuals who die each year. ${ }^{24}$ Disproportionate end-of-life healthcare costs may be related to delayed or prolonged decision making about life-sustaining treatments. ${ }^{3}$

A nationwide shortage of palliative care specialists ${ }^{11}$ requires increased emphasis on primary palliative care in ICU settings. It is imperative to educate ICU professionals on how to integrate the philosophy of palliative care into their clinical practice. ${ }^{1}$ Although a good starting point, educating individual healthcare professionals about the principles of palliative care may not be enough to change the culture of ICU practice. Interprofessional ICU teams must learn how to collaboratively identify and address the complex social, spiritual, emotional, and physical needs of patients and their families throughout the illness trajectory. Furthermore, ICU teams with a shared understanding of palliative care philosophy may be more likely to involve palliative care specialists when patient and family needs are beyond their expertise. ${ }^{13,14}$

To shift ICU culture toward integrated and collaborative palliative care, all stakeholders involved in the process need to have a voice. ${ }^{22,25}$ Interprofessional dialogue is the first step in identifying best practices (or lack thereof) and formulating new directions in research and implementation science that support acceptable and sustainable practice changes. In our scenario, greater communication among nurses and physicians about the palliative care needs of the patient and his wife may have reduced nurse moral distress, even if family decision making and final clinical outcomes were unchanged. There is a need to collaboratively develop policies that support all healthcare professionals in their efforts to deliver compassionate, holistic ICU care that is consistent with patient and family goals.

There is a growing body of evidence supporting palliative specialist involvement and palliative integration in the ICU. ${ }^{9,26-29}$ In a recent cluster randomized crossover trial in a medical ICU, patients in the intervention group who received an early palliative care consultation (within 48 hours of ICU admission) had significantly more transfers to hospice care, fewer ventilator days, and fewer readmissions to the hospital compared with patients receiving usual care. ${ }^{27}$ In a systematic review and meta-analysis of terminally ill patients in the ICU, those in the intervention group receiving palliative care experienced 2.5 fewer days in the ICU compared with usual care. ${ }^{30} \mathrm{In}$ another systematic review of advance care planning and ICU palliative care interventions, findings revealed a trend toward fewer ICU admissions and less time spent in the ICU. ${ }^{31}$ Importantly, there is evidence that palliative specialist involvement may reduce ICU mortality ${ }^{30}$ or does not influence ICU or in-hospital mortality ${ }^{27,32}$ when compared with usual care, suggesting that palliative care does not hasten death. From a cost perspective, Ma et $\mathrm{al}^{27}$ found that there were lower MICU and pharmacy operating costs for those who received an interprofessional early palliative care intervention. Furthermore, in a cost evaluation study, 5 of 8 studies demonstrated a significant reduction in healthcare costs with palliative care consultations in the ICU. ${ }^{32}$ 
The barriers to palliative care delivery in the ICU are well articulated in the literature. ${ }^{8,33-36}$ Documented challenges include unrealistic patient and family expectations and disagreements between patients and families and the ICU team about goals of care $^{8}$; variable provider attitudes about the role of palliative care ${ }^{37}$; differing opinions about what specific triggers should be used for automatic palliative specialist consults ${ }^{36}$; nurse and physician disagreement about whether bedside nurses can request a palliative specialist consult ${ }^{36}$; inadequate support for junior physicians during end-of-life decisions ${ }^{37}$; disagreement among healthcare professionals about who can benefit from palliative care ${ }^{36}$; identification of the best strategies for integrating palliative care in the $\mathrm{ICU}^{8,33}$; and limited metrics to evaluate palliative care integration and collaboration in the delivery of ICU care. ${ }^{15}$ Some of these barriers were apparent in our scenario-specifically, unrealistic family expectations and inadequate communication and collaboration among the team about how to deliver palliative care to Henry and Betty. And yet, there is a paucity of literature on how to overcome these identified barriers.

\section{UNDERSTANDING AND IMPROVING PALLIATIVE INTEGRATION}

There are a number of research directions that could expand our understanding of the impact of palliative care and successful strategies to improve the integration of palliative care in the ICU. Capturing patient and family experiences is a critical step to guide palliative care improvement in the ICU. However, there is limited literature exploring patient and family perceptions of palliative care in acute care, ${ }^{38}$ and to our knowledge, there are no such studies specific to the ICU setting. Important family outcomes, such as family resiliency, meaningmaking, and engagement in decision making, may be influenced by palliative care yet remain inadequately explored in the adult ICU context. ${ }^{39-47}$ There is evidence that patients' preferences for care change over time as their conditions worsen, ${ }^{48}$ suggesting the need for research about how to best elicit evolving care preferences. It is also important to increase our understanding of the expectations and experiences of ICU professionals as they deliver primary palliative care or involve palliative care specialists. This knowledge could bridge the translationto-practice gap by promoting strategic palliative care delivery to decrease suffering among patients, families, and healthcare professionals who are working toward family-engaged palliative care.

With their constant presence at the bedside, nurses may be best positioned to assess unmet palliative care needs of seriously ill patients and their families. ${ }^{49}$ Families develop strong bonds with ICU nurses and share important information that can enhance the decision-making process. However, the unique contributions that nurses make during complex decision making in the ICU have not been fully explored.

Another important direction for research is the role of palliative care specialists and clinical ethics consultants in supporting ICU team members, especially nurses who spend 12 or more continuous hours with patients and their families, during challenging patient cases. To develop effective interventions to integrate palliative care in the ICU, we need to know how ICU teams conceptualize and operationalize primary palliative care. Furthermore, understanding the decision-making processes among ICU teams about when and why they choose to consult palliative care specialists is key to overcoming many of the identified barriers in the literature.

Collaborative palliative care delivery is a critical direction for further study and translation to practice. Intensive care unit teams that consider palliative care specialists as collaborators, rather than "consultants," recognize that palliative care specialists can support them in their mission to elicit patient and family understanding of illness, care preferences, hopes, worries, and values. Collaboration can enhance team members' perception of support during challenging cases. For example, junior physicians report that nursing colleagues and palliative care specialists are important sources of support. ${ }^{37}$ Valuable insights about palliative integration could result from further study of ICU teams that successfully deliver collaborative palliative care and actively partner with palliative care specialists throughout a patient's illness trajectory. Patient and family care is more effective when delivered by an interprofessional team where the unique role and expertise of each member contribute to holistic patient care.$^{50}$ In Ma et al's study, ${ }^{27}$ the early palliative care intervention was delivered by a palliative 
care team composed of a physician, fellow, nurse practitioners, social worker, and a chaplain. This interprofessional team followed enrolled patients throughout their hospitalization; thus, this comprehensive patient and family support may have contributed to the positive outcomes found in this study.

\section{PROMOTING STRATEGIC PALLIATIVE CARE DELIVERY THROUGH A COLLABORATIVE FRAMEWORK: SUGGESTIONS FOR PRACTICE}

It will take concerted efforts from multiple stakeholders to increase patient and family access to palliative care in the ICU. To improve palliative care delivery for all patients and families, ICU teams need to articulate and document the primary palliative care support they provide and how patients and families respond to these interventions. The following are suggestions for ICU teams, healthcare organizations, researchers, and policy makers to reach the important goal of collaborative and integrated palliative care in the ICU.

ICU teams:

1. Normalize interprofessional input, especially from nurses, on goals of care and the decision to consult with palliative care specialists.

2. Engage palliative care specialists in ICU rounds and/or conduct debriefings on challenging case ${ }^{51}$ to support ICU teams.

3. Involve palliative care specialists in simulations to train ICU teams in the delivery of primary palliative care.

Healthcare organizations:

1. Invest in more palliative care specialists who can train ICU teams to deliver primary palliative care and to promote consultation with palliative care specialists for complex cases.

2. Develop organizational practice guidelines and policy statements based on the National Consensus Project Clinical Practice Guidelines for Quality Palliative Care. ${ }^{2}$

3. Use reliable and valid instruments to measure the quality of palliative care in the ICU, such as those created by the Robert Wood Johnson workgroup. ${ }^{52-54}$

4. Create comprehensive process and outcome measures related to palliative care delivery that are meaningful to patients and families, healthcare professionals, and healthcare organizations.

Researchers:

1. Conduct cost-effectiveness studies ${ }^{55}$ on the impact of palliative care interventions in the ICU.

2. Conduct exploratory studies with ICU teams about their understanding of and experiences with collaborative primary palliative care.

3. Use qualitative and quantitative methods to capture and measure the impact of primary and specialty palliative care on ICU patient and family outcomes.

Policymakers:

1. Develop nationally accepted benchmarks to compare the quality of palliative care delivery across healthcare organizations.

2. Create a merit system to designate high-performing hospitals and reward them with federal and state financial compensation.

3. Create financial incentives for healthcare professionals to train to become palliative care specialists.

Call to Action: Translate Evidence Into Practice to Integrate Palliative Care in the ICU Nurses can respond to this call to action by engaging provider colleagues in identifying missed opportunities to deliver primary palliative care and also to partner with palliative care specialists. With their expertise in interprofessional collaboration, palliative care specialists can share strategies with ICU teams about how to work through conflicts collaboratively during challenging patient and family care situations. Nurses are well positioned to lead and support interprofessional ICU teams through the process of palliative care integration. 


\section{CLINICAL IMPLICATIONS}

- Palliative care specialists have the expertise to train and mentor ICU teams to recognize opportunities where ICU healthcare professionals could collaboratively deliver primary palliative care.

- Intensive care unit teams could provide more comprehensive support to patients and families if they partnered with palliative care specialists in their day-to-day practice (rounds, debriefings, and family meetings).

- Engaging all stakeholders in ongoing dialogue about palliative care improvement could galvanize a culture shift in the ICU toward palliative care integration.

\section{References}

1. Ferrell BR, Virani R, Paice JA, Malloy P, Dahlin C. Statewide efforts to improve palliative care in critical care settings. Crit Care Nurse. 2010;30(6):40-45. doi:10.4037/ccn2010248.

2. Ferrell BR, Twaddle ML, Melnick A, Meier DE. National consensus project clinical practice guidelines for quality palliative care guidelines, 4th edition. J Palliat Med. 2018;21(12):1684-1689. doi:10.1089/jpm.2018.0431.

3. Institute of Medicine. Dying in America: Improving Quality and Honoring Individual Preferences Near the End of Life. Washington, DC: National Academies Press; 2015. doi:10.17226/18748.

4. Singer PA, Bowman KW. Quality end-of-life care: a global perspective. BMC Palliat Care. 2002;1(1). doi:10.1186/1472-684X-1-4.

5. Quill TE, Abernethy AP. Generalist plus specialist palliative care-creating a more sustainable model. New England Journal of Medicine. 2013;368(13):1173-1175. doi:10.1056/NEJMp1215620.

6. Schenker Y, Quill TE. Primary palliative care2020. https://www-uptodatecom.proxy.lib.mcw.edu/contents/primary-palliative-care/print. Accessed February 20, 2020.

7. Evans BA, Turner MC, Gloria JN, Pickett LC, Galanos AN. Palliative care consultation is underutilized in critically ill general surgery patients [published online ahead of print July 17, 2019]. Am J Hosp Palliat Care. doi:10.1177/1049909119864025.

8. Kyeremanteng $\mathrm{K}$, Beckerleg $\mathrm{W}$, Wan $\mathrm{C}$, et al. Survey on barriers to critical care and palliative care integration. Am J Hosp Palliat Med. 2020;37(2):108-116. doi:10.1177/1049909119867658.

9. Mun E, Umbarger L, Ceria-Ulep C, Nakatsuka C. Palliative care processes embedded in the ICU workflow may reserve palliative care teams for refractory cases. Am J Hosp Palliat Care. 2018;35(1):60-65. doi:10.1177/1049909116684821.

10. Seaman JB, Barnato AE, Sereika SM, Happ MB, Erlen JA. Patterns of palliative care service consultation in a sample of critically ill ICU patients at high risk of dying. Heart Lung. 2017;46(1):18-23. doi:10.1016/j.hrtlng.2016.08.008.

11. Kamal AH, Wolf SP, Troy J, et al. Policy changes key to promoting sustainability and growth of the specialty palliative care workforce. Health Aff. 2019;38(6):910-918. doi:10.1377/hlthaff.2019.00018.

12. Vuong C, Kittelson S, McCullough L, Yingwei Y, Hartjes T. Implementing primary palliative care best practices in critical care with the care and communication bundle. BMJ Open Qual. 2019;8(3):e000513. doi:10.1136/bmjoq-2018-000513.

13. Aslakson RA, Curtis JR, Nelson JE. The changing role of palliative care in the ICU. Crit Care Med. 2014;42(11):2418-2428. doi:10.1097/CCM.0000000000000573.

14. Aslakson R, Cheng J, Vollenweider D, Galusca D, Smith TJ, Pronovost PJ. Evidence-based palliative care in the intensive care unit: a systematic review of interventions. J Palliat Med. 2014;17(2):219-235.

doi:10.1089/jpm.2013.0409. 
15. Schram AW, Hougham GW, Meltzer DO, Ruhnke GW. Palliative care in critical care settings: a systematic review of communication-based competencies essential for patient and family satisfaction. Am J Hosp Palliat Care. 2017;34(9):887-895. doi:10.1177/1049909116667071.

16. Forozeiya D, Vanderspank-Wright B, Bourbonnais FF, Moreau D, Wright DK. Coping with moral distress-the experiences of intensive care nurses: an interpretive descriptive study. Intensive Crit Care Nurs. 2019;53:23-29. doi:10.1016/j.iccn.2019.03.002.

17. Huffman DM, Rittenmeyer L. How professional nurses working in hospital environments experience moral distress: a systematic review. Crit Care Nurs Clin North Am. 2012;24(1):91-100. doi:10.1016/j.ccell.2012.01.004.

18. McAndrew NS, Leske JS. A balancing act: experiences of nurses and physicians when making end-of-life decisions in intensive care units. Clin Nurs Res. 2015;24(4):357-374. doi:10.1177/1054773814533791.

19. McAndrew NS, Leske J, Schroeter K. Moral distress in critical care nursing: the state of the science. Nurs Ethics. 2018;25(5):552-570. doi:10.1177/0969733016664975.

20. Moss M, Good VS, Gozal D, Kleinpell R, Sessler CN. An official Critical Care Societies Collaborative statement-burnout syndrome in critical care health-care professionals: a call for action. Chest. 2016;150(1):17-26. doi:10.1016/j.chest.2016.02.649.

21. McAndrew NS, Schiffman R, Leske J. A theoretical lens through which to view the facilitators and disruptors of nurse-promoted engagement with families in the ICU. J Fam Nurs. 2020;26(3):190-212. doi:10.1177/1074840720936736.

22. McAndrew NS, Hardin JB. Giving nurses a voice during ethical conflict in the ICU [published online ahead of print July 14, 2020]. Nurs Ethics. doi:10.1177/0969733020934148.

23. Michalsen A, Long AC, DeKeyser Ganz F, et al. Interprofessional shared decision-making in the ICU: a systematic review and recommendations from an expert panel. Crit Care Med. 2019;47(9):1258-1266. doi:10.1097/CCM.0000000000003870.

24. Feeley TW. The value of ICU care at the end of life. NEJM Catalyst. September 28, 2016. https://catalyst.nejm.org/value-icu-care-end-of-life/. Accessed February 20, 2020.

25. McAndrew NS, McCracken C, Szabo A, Narayanan B, Peltier W, Leske J. Evaluating the outcomes of an organizational initiative to expand end-of-life resources in intensive care units with palliative support tools and floating hospice. Dimens Crit Care Nurs. 2020;39(4):219-235. doi:10.1097/DCC.0000000000000423.

26. Adler K, Schlieper D, Kindgen-Milles D, et al. Integration of palliative care into intensive care: systematic review. Anaesthesist. 2017;66(9):660-666. doi:10.1007/s00101-017-0326-0.

27. Ma J, Chi S, Buettner B, et al. Early palliative care consultation in the medical ICU: a cluster randomized crossover trial. Crit Care Med. 2019;47(12):1707-1715. doi:10.1097/CCM.0000000000004016.

28. Romano AM, Gade KE, Nielsen G, et al. Early palliative care reduces end-of-life intensive care unit (ICU) use but not ICU course in patients with advanced cancer. Oncologist. 2017;22(3):318-323. doi:10.1634/theoncologist.2016-0227.

29. Zalenski RJ, Jones SS, Courage $C$, et al. Impact of palliative care screening and consultation in the ICU: a multihospital quality improvement project. J Pain Symptom Manage. 2017;53(1):5-12.e3. doi:10.1016/j.jpainsymman.2016.08.003.

30. Martins BDCPCC, Oliveira RA, Cataneo AJM. Palliative care for terminally ill patients in the intensive care unit: systematic review and metaanalysis. Palliat Support Care. 2017;15(3):376-383. doi:10.1017/S1478951516000584.

31. Khandelwal N, Kross EK, Engelberg RA, Coe NB, Long AC, Curtis JR. Estimating the effect of palliative care interventions and advance care planning on ICU utilization: a systematic review. Crit Care Med. 2015;43(5):1102-1111. doi:10.1097/CCM.0000000000000852. 
32. Kyeremanteng K, Gagnon LP, Thavorn K, Heyland D, D'Egidio G. The impact of palliative care consultation in the ICU on length of stay: a systematic review and cost evaluation. J Intensive Care Med. 2018;33(6):346-353. doi:10.1177/0885066616664329.

33. Beernaert K, Deliens L, Pardon K, et al. What are physicians' reasons for not referring people with life-limiting illnesses to specialist palliative care services? A nationwide survey. PLOS ONE. 2015;10(9):e0137251. doi:10.1371/journal.pone.0137251.

34. Gatta B, Turnbull J. Providing palliative care in the medical ICU: a qualitative study of MICU physicians' beliefs and practices. Am J Hosp Palliat Med. 2018;35(10):1309-1313. doi:10.1177/1049909118771378.

35. Visser M, Deliens L, Houttekier D. Physician-related barriers to communication and patient- and familycentred decision-making towards the end of life in intensive care: a systematic review. Crit Care. 2014;18(6):604. doi:10.1186/s13054-014-0604-z.

36. Wysham NG, Hua M, Hough CL, et al. Improving ICU-based palliative care delivery: a multicenter, multidisciplinary survey of critical care clinician attitudes and beliefs. Crit Care Med. 2017;45(4):e372e378. doi:10.1097/CCM.0000000000002099.

37. Bharmal A, Morgan T, Kuhn I, Wee B, Barclay S. Palliative and end-of-life care and junior doctors': a systematic review and narrative synthesis [published online ahead of print November 13, 2019]. BMJ Support Palliat Care. doi:10.1136/bmjspcare-2019-001954.

38. Robinson J, Gott M, Ingleton C. Patient and family experiences of palliative care in hospital: what do we know? An integrative review. Palliat Med. 2014;28(1):18-33. doi:10.1177/0269216313487568.

39. Adelstein KE, Anderson JG, Gill Taylor A. Importance of meaning-making for patients undergoing hematopoietic stem cell transplantation. Oncol Nurs Forum. 2014;41(2):E172-E184. doi:10.1188/14.ONF.E172-E184.

40. Bajjani-Gebara J, Hinds P, Insel K, Reed P, Moore K, Badger T. Well-being, self-transcendence, and resilience of parental caregivers of children in active cancer treatment: where do we go from here?Cancer Nurs. 2019;42(5):E41-E52. doi:10.1097/NCC.0000000000000662.

41. Burns KEA, Misak C, Herridge M, Meade MO, Oczkowski S. Patient and family engagement in the ICU. Untapped opportunities and underrecognized challenges. Am J Respir Crit Care Med. 2018;198(3):310319. doi:10.1164/rccm.201710-2032Cl.

42. Coward DD, Reed PG. Self-transcendence: a resource for healing at the end of life. Issues Ment Health Nurs. 1996;17(3):275-288. doi:10.3109/01612849609049920.

43. Kruser JM, Benjamin BT, Gordon EJ, et al. Patient and family engagement during treatment decisions in an ICU: a discourse analysis of the electronic health record. Crit Care Med. 2019;47(6):784-791. doi:10.1097/CCM.0000000000003711.

44. Laurent A, Reignier J, Le Gouge A, et al. "You helped me keep my head above water" - experience of bereavement research after loss of a loved one in the ICU: insights from the ARREVE study. Intensive Care Med. 2019;45(9):1252-1261. doi:10.1007/s00134-019-05722-x.

45. Meert KL, Eggly S, Kavanaugh K, et al. Meaning making during parent-physician bereavement meetings after a child's death. Health Psychol. 2015;34(4):453-461. doi:10.1037/hea0000153.

46. Patterson JM. Integrating family resilience and family stress theory. J Marriage Fam. 2002;64(2):349-360. doi:10.1111/j.1741-3737.2002.00349.x.

47. Wong $\mathrm{P}$, Liamputtong $\mathrm{P}$, Koch $\mathrm{S}$, Rawson $\mathrm{H}$. Searching for meaning: a grounded theory of family resilience in adult ICU. J Clin Nurs. 2019;28(5-6):781-791. doi:10.1111/jocn.14673.

48. Alyami HM, Chan RJ, New K. End-of-life care preferences for people with advanced cancer and their families in intensive care units: a systematic review. Support Care Cancer. 2019;27(9):3233-3244. doi:10.1007/s00520-019-04844-8. 
49. Bennett F, O'Conner-Von S. Communication interventions to improve goal-concordant care of seriously ill patients: an integrative review. J Hosp Palliat Nurs. 2020;22(1):40-48. doi:10.1097/NJH.0000000000000606.

50. Fernando G, Hughes S. Team approaches in palliative care: a review of the literature. Int J Palliat Nurs. 2019;25(9):444-451. doi:10.12968/ijpn.2019.25.9.444.

51. Braus N, Campbell TC, Kwekkeboom KL, et al. Prospective study of a proactive palliative care rounding intervention in a medical ICU. Intensive Care Med. 2016;42(1):54-62. doi:10.1007/s00134-015-4098-1.

52. Clarke EB, Curtis JR, Luce JM, et al. Quality indicators for end-of-life care in the intensive care unit. Crit Care Med. 2003;31(9):2255-2262. doi:10.1097/01.CCM.0000084849.96385.85.

53. Clarke EB, Luce JM, Curtis JR, et al. A content analysis of forms, guidelines, and other materials documenting end-of-life care in intensive care units. J Crit Care. 2004;19(2):108-117. doi:10.1016/j.jcrc.2004.05.001.

54. Ho LA, Engelberg RA, Curtis JR, et al. Comparing clinician ratings of the quality of palliative care in the intensive care unit. Crit Care Med. 2011;39(5):975-983. doi:10.1097/CCM.0b013e31820a91db.

55. Wilcox ME, Vaughan K, Chong CAKY, Neumann PJ, Bell CM. Cost-effectiveness studies in the ICU: a systematic review. Crit Care Med. 2019;47(8):1011-1017. doi:10.1097/CCM.0000000000003768. 